\title{
Prevention of Cap-Locking of Syrup Product by Treating the Manufacturing Process of Sugar Syrup with Citric Acid Monohydrate
}

\author{
Mia Mohammad Dulal ${ }^{1}$, Md. Kaisarul Islam², Abu Asad Chowdhury ${ }^{2}$ \\ and Jakir Ahmed Chowdhury ${ }^{3}$
}

\author{
${ }^{1}$ Julphar Gulf Pharmaceuticals Ltd, R.A.K.,UAE. \\ ${ }^{2}$ Department of Pharmaceutical Chemistry, Faculty of Pharmacy, University of Dhaka, Dhaka-1000, Bangladesh \\ ${ }^{3}$ Department of Pharmaceutical Technology, Faculty of Pharmacy, University of Dhaka, Dhaka-1000, Bangladesh
}

Received: May 13, 2016; Accepted: June 29, 2016; Published (Web): July 31, 2016

\begin{abstract}
The aim of the study was to prevent crystallization of sucrose on the bottle neck and cap of sugar syrup containing products by treating the manufacturing process with citric acid monohydrate. Diphenhydramine $\mathrm{HCl}$ syrup was selected as a model product for the experiment. Sugar syrup (66\% w/w sucrose) and partially inverted sugar syrup (in which 66\% w/w sucrose was treated with citric acid monohydrate for partially conversion of sucrose into invert sugars) were prepared and the content of invert sugar of both the sugar syrups were determined. Sugar syrup and citric acid monohydrate treated sugar syrup (partially inverted) were considered as control and test sugar syrup, respectively which were used to manufacture the Diphenhydramine $\mathrm{HCl}$ syrup product. The Diphenhydramine $\mathrm{HCl}$ syrup product that prepared using sugar syrup was considered as control syrup product and that was prepared using citric acid monohydrate treated sugar syrup (partially inverted) was considered as the test syrup product. Then experiments were designed in such a way that both control (sugar syrup and product prepared by it) and test samples (partially inverted syrup and product prepared by it) were spread on open petridishes and also spread on the neck of filled bottle, inside of caps and the bottles, which were kept at room temperature $\left(25^{\circ} \mathrm{C}\right)$ for 2 weeks observation. At zero time and after two weeks, crystal growths of sucrose for each experiment were checked visually. No crystal was observed in open petridishes and bottle necks of partially inverted sugar syrup of Diphenhydramine $\mathrm{HCl}$ syrup prepared by using partially inverted sugar syrup, where content of invert sugars was more than $75 \%$ w/w, but remarkable crystal growths were found in open petridishes and bottle necks of sugar syrup and Diphenhydramine $\mathrm{HCl}$ syrup prepared by using sugar syrup, where the content of invert sugars was less than $15 \% \mathrm{w} / \mathrm{w}$.
\end{abstract}

Key words: Sugar syrup, Inverted sugar syrup, Citric acid monohydrate, Crystal growth

\section{Introduction}

Sucrose is a natural sweetening agent, very soluble in water \& crystallizes from the medium in the anhydrous form (Lemieux et al., 1953). It consists of two monosaccharides, $\alpha$-glucose and fructose, joined by a glycosidic bond (-o-). Hydrolysis of sucrose yields Dglucose and D-fructose; the process is called inversion and the sugar mixture produced is known as invert sugar because, although sucrose itself rotates plane-polarized light to the right, the mixture "inverts" this light by rotating it to the left. This inversion is achieved by heating a sucrose solution, and applying either a solution of acid or enzymes (Rowe et al., 2004). The syrup is neutralized when the desired level of inversion is reached. Optical rotation for sucrose is $[\alpha]=+66.4^{\circ}$ (Moreau et al., 2000), for glucose $[\alpha]=+53^{\circ}$, for fructose $[\alpha]=-92^{\circ} \&$ for resultant equilibrium mixture $[\alpha]=-20.6^{\circ}$ (Nasef et al., 2004). Invert sugar has a lower water activity than that of sucrose, so inverts provide more powerful preserving qualities (shelf life). Sucrose is less soluble than glucose and fructose. Invert sugar is more hygroscopic, so it can be used to make a product that stays moist longer than if sucrose was used and is less prone to crystallization (Hahn-Hagerdal et al., 1983).

Correspondence to: Jakir Ahmed Chowdhury; Tel.: +880-01556333050; E-mail: jakir@du.ac.bd 


\section{Inversion reaction:}

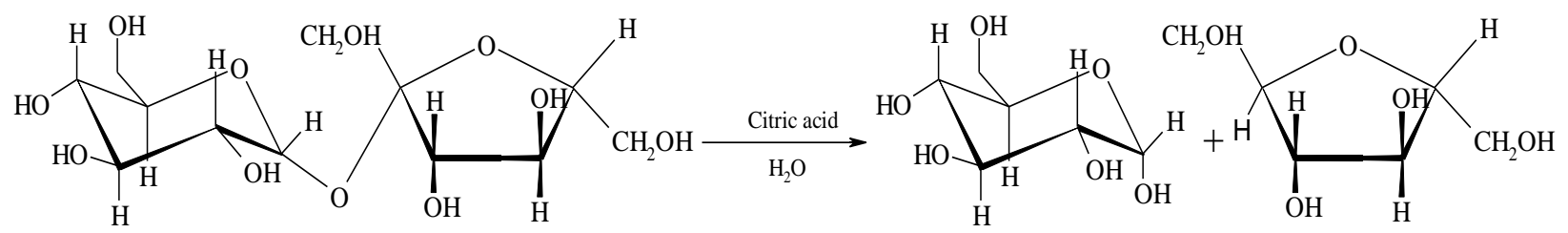

Commercial liquid invert sugars are prepared as different mixtures of sucrose and invert sugar. For example total invert sugar is half glucose and half fructose, while $50 \%$ invert sugar (half of the sucrose has been inverted) is one-half sucrose, one-quarter glucose and one-quarter fructose. Invert sugar is used mainly by food manufacturers to retard the crystallization of sugar and to retain moisture in the packaged food.

\section{Materials and Methods}

Active ingredient and excipients used in this study were of pharmaceutical grades. All others chemicals and solvent were of analytical grade and collected from the local sources.

Preparation of sugar syrup (66 \% w/w): $2 \mathrm{~kg}$ sugar syrup was prepared by dissolving $1.32 \mathrm{~kg}$ of sucrose in $0.68 \mathrm{~kg}$ of hot purified water $\left(70 \pm 1^{\circ} \mathrm{C}\right)$ in a water bath. Then the sucrose solution was heated at 90 $\pm 1{ }^{\circ} \mathrm{C}$ for 45 minutes. Afterwards, the sugar syrup was cooled to $40{ }^{\circ} \mathrm{C}$. Final weight of sugar syrup was adjusted to $2 \mathrm{~kg}$ with purified water and considered as control sugar syrup and labeled as batch no 'A 001'.

Preparation of partially inverted sugar syrup (66 $\% w / w): 2 \mathrm{~kg}$ partially inverted sugar syrup was prepared by dissolving $1.32 \mathrm{~kg}$ of sucrose and $0.44 \mathrm{~g}$ of citric acid monohydrate in $0.66 \mathrm{~kg}$ of hot purified water $\left(70 \pm 1{ }^{\circ} \mathrm{C}\right)$ in a water bath. Then the sucrose solution was heated at $90 \pm 1^{\circ} \mathrm{C}$ for 45 minutes. Afterwards, the sugar syrup (partially inverted) was cooled to $40^{\circ} \mathrm{C}$. Final weight of sugar syrup (partially inverted) was adjusted to $2 \mathrm{~kg}$ with purified water and considered as test sugar syrup (partially inverted) and labeled as batch no 'A 002'.

Preparation of Diphenhydramine $\mathrm{HCl}$ syrup using sugar syrup: $1.669 \mathrm{~kg}$ sugar syrup (batch no. A 001) was taken in a manufacturing beaker. $4.8 \mathrm{~g}$ of Nabenzoate, $3.92 \mathrm{~g}$ of saccharin-Na, $22.8 \mathrm{~g}$ of Na-citrate were dissolved in $75 \mathrm{~g}$ of purified water in a glass beaker and the solution was added to the manufacturing beaker with stirring. $4.4 \mathrm{~g}$ of citric acid monohydrate and $5.4 \mathrm{~g}$ of Diphenhydramine $\mathrm{HCl}$ (label claim 13.5 $\mathrm{mg} / 5 \mathrm{~mL}$ ) were dissolved in $15 \mathrm{~g}$ of purified water in a glass beaker with stirring and the solution was added to the manufacturing beaker with stirring. $52.6 \mathrm{~g}$ of ammonium chloride was dissolved in $80 \mathrm{~g}$ of purified water in a beaker and added to the manufacturing beaker with stirring. $140 \mathrm{~g}$ of glycerol was added to the manufacturing beaker with stirring. $0.44 \mathrm{~g}$ of menthol and $2 \mathrm{~g}$ of raspberry flavor were dissolved in $10 \mathrm{~g}$ of alcohol in a glass beaker and the flavor solution was added to the manufacturing beaker with stirring. $6 \mathrm{~g}$ of caramel color was dissolved in $20 \mathrm{~g}$ of purified water and the color solution was added to the manufacturing beaker with stirring. The volume was adjusted to 2 litre with purified water. Thus prepared syrup was considered as control syrup product and labeled as batch no "P 001".

Preparation of Diphenhydramine $\mathrm{HCl}$ syrup using partially inverted sugar syrup: $1.669 \mathrm{~kg}$ partially inverted sugar (batch no. A 002) was taken in a manufacturing beaker. $4.8 \mathrm{~g}$ of Na-benzoate, $3.92 \mathrm{~g}$ of saccharin-Na, $22.8 \mathrm{~g}$ of Na-citrate were dissolved in $75 \mathrm{~g}$ of purified water in a glass beaker and the solution was added to the manufacturing beaker with stirring. $4.4 \mathrm{~g}$ of citric acid monohydrate and $5.4 \mathrm{~g}$ of Diphenhydramine $\mathrm{HCl}$ (label claim $13.5 \mathrm{mg} / 5 \mathrm{~mL}$ ) were dissolved in $15 \mathrm{~g}$ of purified water in a glass beaker with stirring and the solution was added to the manufacturing beaker with stirring. $52.6 \mathrm{~g}$ of ammonium chloride was dissolved in $80 \mathrm{~g}$ of purified water in a beaker and added to the manufacturing beaker with stirring. $140 \mathrm{~g}$ of glycerol 
was added to the manufacturing beaker with stirring. $0.44 \mathrm{~g}$ of menthol and $2 \mathrm{~g}$ of raspberry flavor were dissolved in $10 \mathrm{~g}$ of alcohol in a glass beaker and the flavor solution was added to the manufacturing beaker with stirring. $6 \mathrm{~g}$ of caramel color was dissolved in $20 \mathrm{~g}$ of purified water and the color solution was added to the manufacturing beaker with stirring. The volume was adjusted to 2 litre with purified water. Thus prepared syrup was considered as test syrup product and labeled as batch no "P 002".

Physical test of syrups and syrup products: Appearance and $\mathrm{pH}$ of sugar syrup (A001), partially inverted sugar syrup (A002), Diphenhydramine $\mathrm{HCl}$ using sugar syrup (P001) and Diphenhydramine $\mathrm{HCl}$ using partially inverted sugar syrup (P002) were checked and recorded. $40 \mathrm{~g}$ from each sugar syrup (A001) \& partially inverted sugar syrup (A002) were kept in opened glass petridish at room temperature. Initial and 1 week observation for crystal growth of sucrose in the syrups at room temperature were monitored \& results were recorded. Here sugar syrup \& partially inverted sugar syrup were considered as control \& test sample respectively. Similarly, $40 \mathrm{gm}$ from each control syrup product (P 001) and test syrup product (P 002) were kept in opened petridish at room temperature. Initial and 1 week observation for crystal growth of sucrose were monitored \& results were recorded. Similarly, crystal growth was also observed after filling of the sample A001, A002, P001 and P002 into the caplocked glass bottles after two weeks at room temperature.

Determination of content of invert sugars in syrups: Content of invert sugars for sugar syrup (A001) \& partially inverted sugar syrup (A002) were determined by using the testing method of Invert sugar-BP 2007.

\section{Results and Discussion}

Determination of physical characteristics and content of invert sugar: The appearance of the sugar syrup (both control, A001 and test A002) were clear, pale yellow to brownish yellow while of DPH (Diphenhydramine $\mathrm{HCl}$ ) syrup product (both control, P001 and test, P002) were clear and red in color (Table-1). The percentage of invert sugar in sugar syrups (A001 and A002) were $10.2 \%$ and $79.1 \%$ respectively (Table 2). The $\mathrm{pH}$ range of sample A001, $\mathrm{P} 001$ and $\mathrm{P} 002$ were 5.1 to 5.2 where as $\mathrm{pH}$ of sample A002 was 3.5 due to treatment with Citric acid monohydrate (Table 1).

Table 1. Appearance and pH of sugar syrups (A 001 \& A 002) and DPH syrup (P $001 \&$ P002).

\begin{tabular}{lllll}
\hline Test parameter & A 001 & A 002 & P 001 & P 002 \\
\hline \multirow{2}{*}{ Appearance } & clear, pale yellow to & clear, pale yellow & \multirow{2}{*}{ Clear, red color } & Clear, red color \\
pH & brownish color & to brownish color & 5.1 & 5.12 \\
\hline
\end{tabular}

Table 2. Content of invert sugars.

\begin{tabular}{l|l|l}
\hline Test parameter & A 001 & A 002 \\
\hline $\begin{array}{l}\text { Content of } \\
\text { invert sugars }\end{array}$ & $10.2 \%$ & $79.1 \%$ \\
\hline
\end{tabular}

\section{Determination of crystal growth in different formulations:}

In case of open petridishes: The photos reveal that no crystal was present in the opened petridishes of sugar syrup (control, A001) and partially inverted sugar syrup (Test, A002) initially (at zero time) at room temperature (Table 3, Figure 1). After 1 week, crystals of sucrose grew in the opened petridish of sugar syrup
(A001), which contained $10.2 \%$ of invert sugars. On the other hand, after 1 week, no crystals were found in opened petridish of partially inverted sugar syrup (A002) that contained $79.1 \%$ of invert sugars (Table 3, Figure 1). In case of DPH syrup product prepared with sugar syrup (P001) and with partially inverted sugar (P002), the photos reveal that no crystal was present in the opened petridishes of P001 and P002 initially (at zero time). Crystal growth was found in the opened petridish of DPH syrup product prepared with sugar syrup (Control, P001) after 1 week, but no crystal was observed in the opened petridish of DPH syrup product 

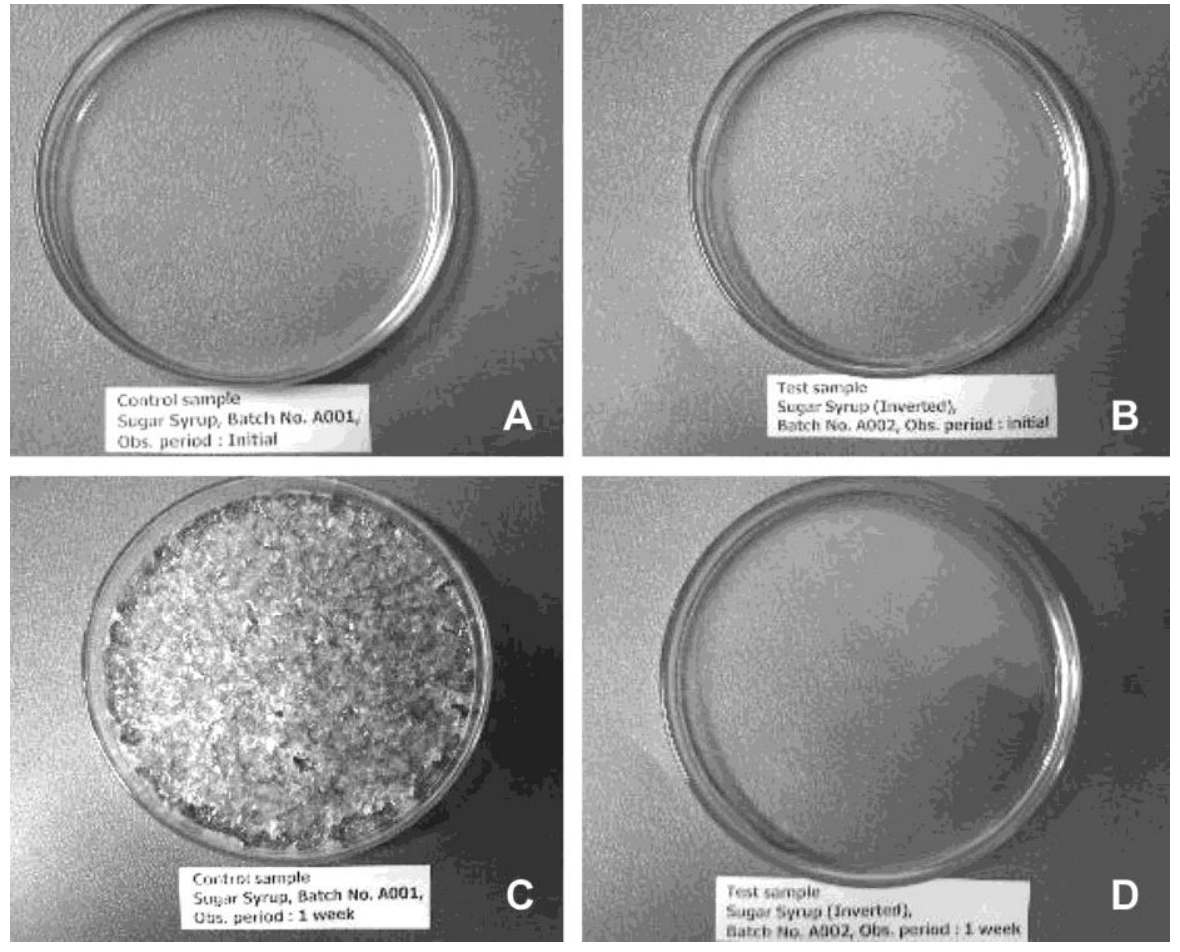

Figure 1. Photos representing crystal growth of sugar syrup \& partially inverted sugar syrup at zero time and after 1 week (at room temperature). A. Sugar syrup (Control, A001) at zero time, B. Partially inverted sugar syrup (Test, A002) at zero time, C. Sugar syrup (Control, A001) after 1week, D. Partially inverted sugar syrup (Test, A002) after 1week.
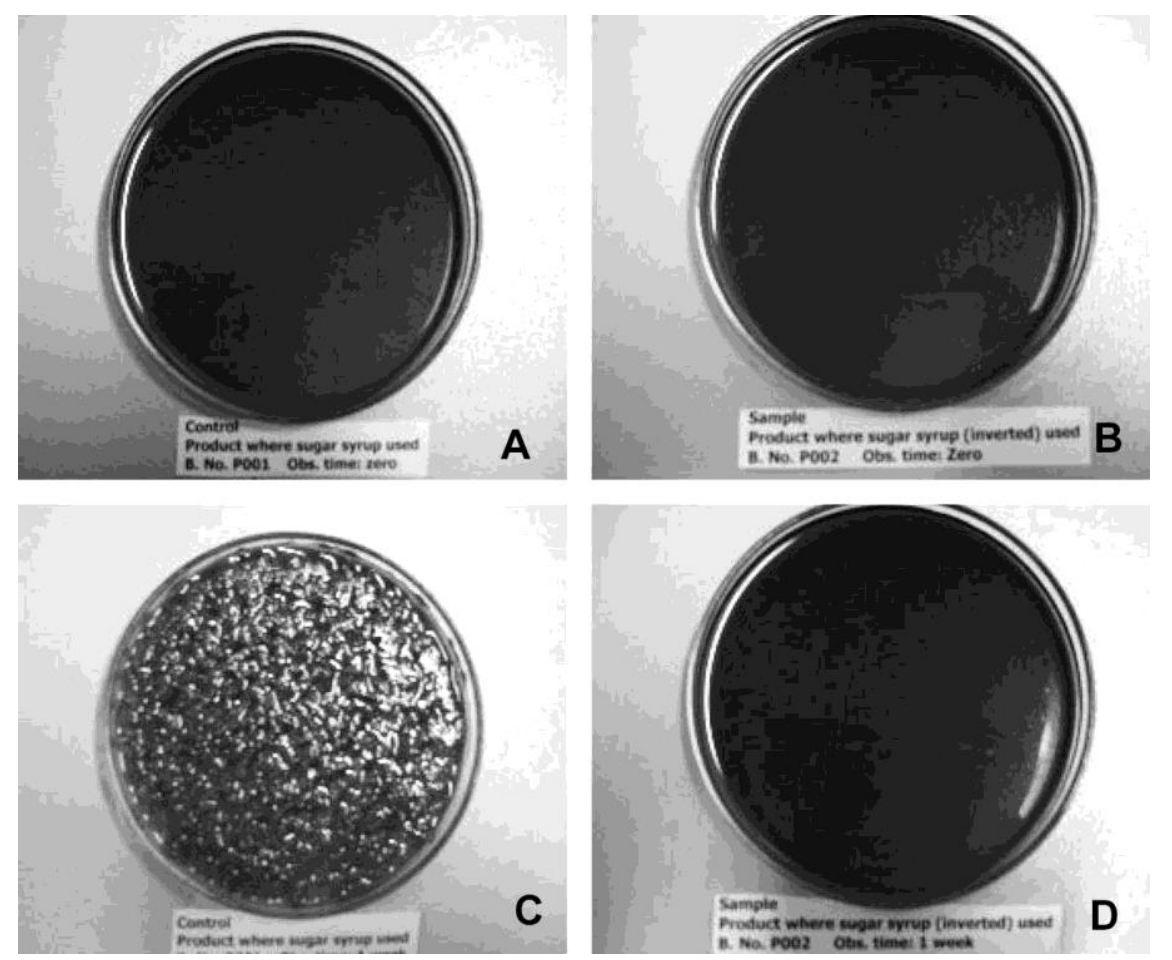

Figure 2. Photos representing crystal growth of DPH with sugar syrup \& partially inverted sugar syrup at zero time and after 1 week (at room temperature). A. DPH with sugar syrup (Control, P001) at zero time, B. DPH with inverted sugar syrup (Test, P002) at zero time, C. DPH with sugar syrup (Control, P001) after 1 week, D. DPH with inverted sugar syrup (Test, P002) after 1 week. 

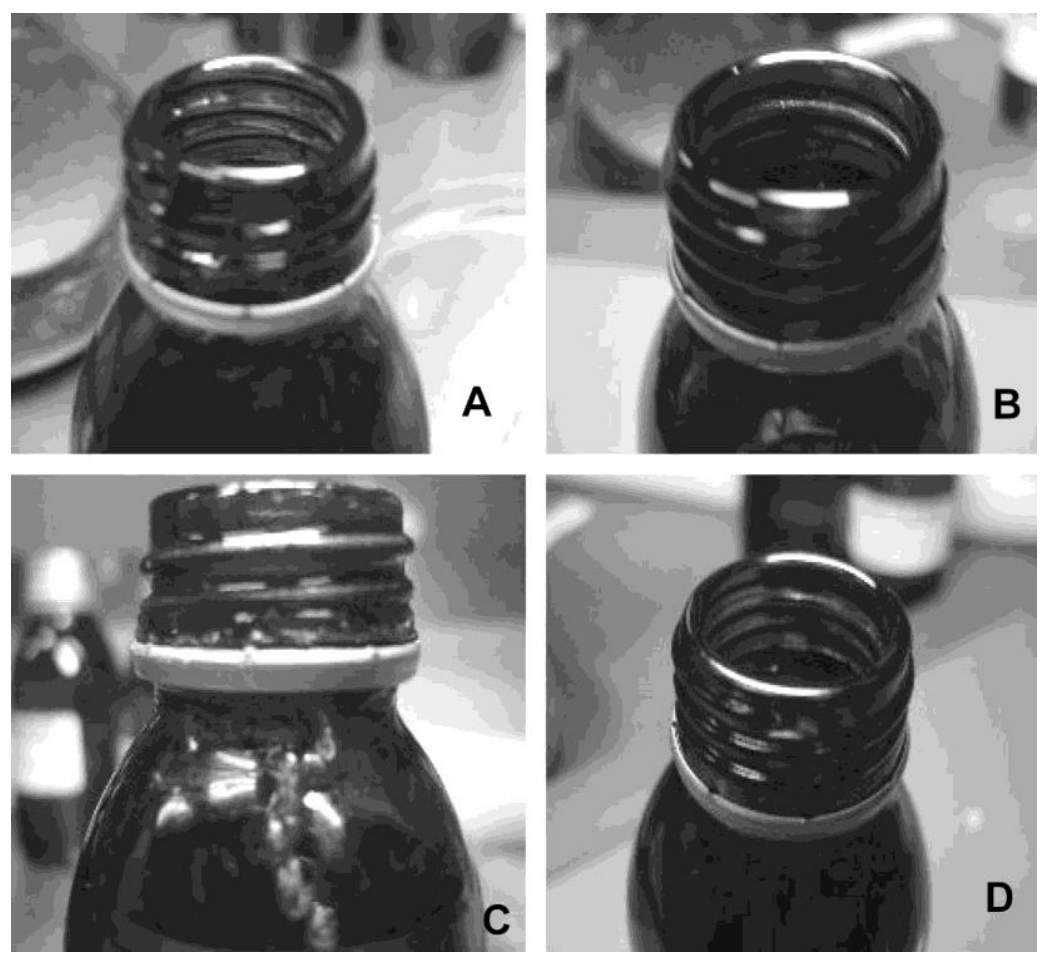

Figure 3. Photos representing crystal growth of sugar syrup \& partially inverted sugar syrup spread inside cap and on bottle neck at zero time and after 2 weeks (at room temperature). A. Sugar syrup (control, A001) at zero time, B. Partially inverted sugar syrup (Test, A002) at zero time, C. Sugar syrup (Control, A001) after 2 week, D. Partially inverted sugar syrup (Test, A002) after 2 week.
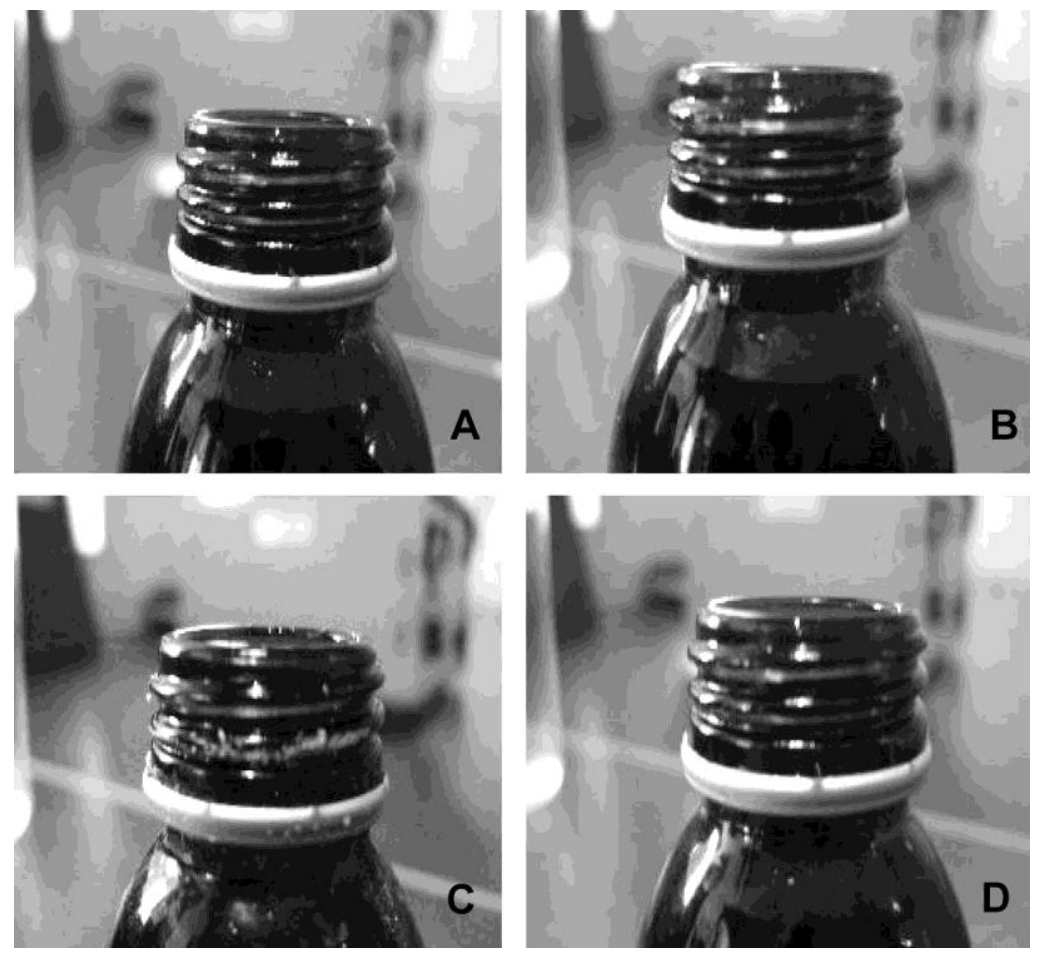

Figure 4. Photos representing crystal growth of DPH with sugar syrup \& partially inverted sugar syrup spread inside cap and on bottle neck at zero time and after 2 weeks (at room temperature). A. DPH with sugar syrup (Control, P001) at zero time, B. DPH with inverted sugar syrup (Test, P002) at zero time, C. DPH with sugar syrup (Control, P001) after 2 week, D. DPH with inverted sugar syrup (Test, P002) after 2 week. 
prepared with sugar syrup (Test, P002) (Table 3, Figure 2). In sugar syrup and syrup product prepared by it (control samples, A001 \& P001), the \% of content of sucrose is more, but in partially inverted sugar syrup and syrup product prepared by it (test sample A002 \& P002), the \% of content of sucrose is less and content of invert sugars are more. The invert sugars are more soluble than that of sucrose and have less tendency to reform crystal structure when solvent evaporates. The more solubility and fewer tendencies of invert sugars to reform crystal structure prevent the crystal formation in both sugar syrup (A002) and DPH syrup product (P002).

Table 3. Observation of crystal growth in A 001, A 002, P 001 and P 002 for controlled and test samples, respectively.

\begin{tabular}{lllllllll}
\hline \multirow{2}{*}{$\begin{array}{l}\text { Observation } \\
\text { parameter }\end{array}$} & \multicolumn{2}{c}{ A 001 } & \multicolumn{2}{c}{ A 002 } & P 001 & P 002 \\
\cline { 2 - 8 } & Zero time & 1 week & Zero time & 1 week & Zero time & 1 week & Zero time & 1 week \\
\hline $\begin{array}{l}\text { Crystal } \\
\text { growth of } \\
\text { sucrose }\end{array}$ & $\begin{array}{l}\text { Presence of } \\
\text { no crystal }\end{array}$ & $\begin{array}{l}\text { Crystal } \\
\text { found }\end{array}$ & $\begin{array}{l}\text { Presence of } \\
\text { no crystal }\end{array}$ & $\begin{array}{l}\text { No crystal } \\
\text { found }\end{array}$ & $\begin{array}{l}\text { Presence of } \\
\text { no crystal }\end{array}$ & $\begin{array}{l}\text { Crystal } \\
\text { found }\end{array}$ & $\begin{array}{l}\text { Presence of no crystal } \\
\text { no crystal } \\
\text { found }\end{array}$ \\
\hline
\end{tabular}

Table 4. Observation of crystal growth inside cap and on of filled bottle neck in A 001, A $002, P 001$ and P 002 for controlled and test samples, respectively.

\begin{tabular}{lllllllll}
\hline \multirow{2}{*}{$\begin{array}{l}\text { Observation } \\
\text { parameter }\end{array}$} & \multicolumn{2}{c}{ A 001 } & \multicolumn{2}{c}{ A 002 } & \multicolumn{2}{c}{ P 001 } & P 002 \\
\cline { 2 - 8 } & Zero time & 2 week & Zero time & 2 week & Zero time & 2 week & Zero time & 2 week \\
\hline $\begin{array}{l}\text { Crystal } \\
\text { growth of } \\
\text { sucrose }\end{array}$ & $\begin{array}{l}\text { Presence of } \\
\text { no crystal }\end{array}$ & $\begin{array}{l}\text { Crystal } \\
\text { found }\end{array}$ & $\begin{array}{l}\text { Presence of } \\
\text { no crystal }\end{array}$ & $\begin{array}{l}\text { No crystal } \\
\text { found }\end{array}$ & $\begin{array}{l}\text { Presence of } \\
\text { no crystal }\end{array}$ & $\begin{array}{l}\text { Crystal } \\
\text { found }\end{array}$ & $\begin{array}{l}\text { Presence of } \\
\text { no crystal }\end{array}$ & $\begin{array}{l}\text { No crystal } \\
\text { found }\end{array}$ \\
\hline
\end{tabular}

In case of cap-locked glass bottle: The photos reveal no crystal grew inside cap \& on bottle neck of sugar syrup (control, A001) and partially inverted sugar syrup (test, A002) initially (at zero time) at room temperature (Table 4, Figure 3A, 3B). After 2 weeks, crystals of sucrose grew inside cap $\&$ on bottle neck of sugar syrup (control, A001) at room temperature (Table 4, Figure 3C). On the other hand, after 2 weeks, crystals did not grow inside cap \& on bottle neck of partially inverted sugar syrup (test, A002) at room temperature (Table 4, Figure 3D). Similarly in case of DPH syrup product prepared with sugar syrup (control, P001) and partially invert sugar (test, P002), the photos reveal that no crystal was present in the opened petridishes of P001 and P002 initially (at zero time) at room temperature (Table 4, Figure 4A, 4B). Crystal growth was found on the bottle neck of DPH syrup product prepared with sugar syrup (Control, P001) after 2 weeks, but no crystal was observed on the bottle neck of DPH syrup product prepared with sugar syrup (Test, P002) (Table 4, Figure 4C, 4D). Sugar syrup (control, A001) and product prepared by it (control,
P001) spread inside cap and on bottle neck resulted crystal of sucrose due to evaporation of water from the spread sugar syrup and also due to nature of crystal formation habit of sucrose. Partially inverted sugar syrup (test sample, A002) and product prepared by it (test P002) spread inside cap and on bottle neck did not result crystal of sucrose even after evaporation of water from the spread syrup (Figure 4). The crystal does not form, because in partially inverted sugar syrup, sucrose is partially converted into glucose and fructose and these invert sugars have more solubility and fewer tendencies to form crystal.

\section{Conclusion}

To reduce bitterness of drugs and enhance palatabity, sucrose is sometimes used at higher concentration. Normally sucrose remained dissolved in the solvent of the product and does not form crystals. But when solvent of syrup product is evaporated on the bottle neck, sucrose is crystallized and cap-locking of bottle is seen. To prevent crystals on bottle neck of product, sugar syrup was processed using citric acid 
monohydrate, which partially hydrolyze sucrose into glucose and fructose. Glucose and fructose are more soluble than sucrose and their water activity is more than sucrose, that's why invert sugars do not form crystal. This technique might be helpful to prevent bottle neck locking of different liquid pharmaceutical product using sucrose at high concentration as palatable agent.

\section{References}

Hahn-Hagerdal, B., Skoog, K. and Mattiasson, B. 1983. The utilization of solid superacids for hydrolysis of glycosidic bonds in di- and polysaccharides: a model study on cellobiose, sucrose, and starch. Eur. J. Microbiol. Biotechnol. 17, 344-347.
Lemieux, R.U. and Huber, G. 1953. A chemical synthesis of sucrose. J. Am. Chem. Soc. 75, 4118-4121.

Moreau, C., Durand, R., Alies, F., Cotillon, M., Frutz, T. and Theleyre, M.E. 2000. Hydrolyssi of sucrose in presence of H-form zeolites, Ind. Crops Products 11, 237-239.

Nasef, M.M., Saidi, H. and Senna, M.M. 2005. Hydrolysis of sucrose by radiation grafted sulfonic acid membranes. Chem. Eng. J. 108 (1-2), 13-17.

Rowe, R.C., Sheskey, P.J. and Owen, S.C. 2004. Sucrose>Related substance>invert sugar Pharmaceutical Excipients. 